\title{
Pre-Hospital Glyceryl Trinitrate: Potential for Use in Intracerebral Hemorrhage
}

Jason J Chang ${ }^{1 *}$ and Nerses Sanossian ${ }^{1,2}$

${ }^{1}$ Department of Neurology, University of Southern California, USA

${ }^{2}$ Roxanna Todd Hodges Comprehensive Stroke Clinic, University of Southern California, USA

\begin{abstract}
Background: Intracerebral hemorrhage is associated with poor clinical outcome and high mortality. Research and treatment modalities have focused on the expansion of the primary hematoma through blood pressure control and activation of coagulation factors. However, clinical trials have failed to show decreased rates of death or disability in intracerebral hemorrhage following hospital initiation of blood pressure control. However, as clinical deterioration often occurs immediately after onset, pre-hospital initiation of blood pressure control may be more ideal.
\end{abstract}

Methods: Relevant terms in the National Library of Medicine PubMed database and selected research including basic science, translational reports, meta-analyses, and clinical studies were searched.

Results: Trends indicating improved clinical outcome in intracerebral hemorrhage after hospital-initiated intensive systolic blood pressure control (goal $<140 \mathrm{mmHg}$ ) have been demonstrated. Statistical significance may not have been obtained because of late treatment times of blood pressure control that approached median 4-6 hours after clinical onset. One trial utilizing glyceryl trinitrate in the pre-hospital setting has been shown to significantly decrease blood pressure within fifteen minutes and improve 90-day clinical outcome.

Conclusions: Glyceryl trinitrate represents an ideal pre-hospital blood pressure medication because it can be delivered via sublingual or transdermal routes, has a quick and graded onset of action, has neuroprotective effects, maintains cerebral perfusion, and has an established record of safety. As intracerebral hemorrhage requires prompt action to prevent clinical deterioration, more emphasis on pre-hospital therapies for blood pressure reduction will become essential in future therapies.

Keywords: Intracerebral hemorrhage; Antihypertensive; Glyceryl trinitrate; Nitroglycerin; Treatment; Blood pressure

\section{Introduction}

Of an estimated 795,000 new strokes per year, intracerebral hemorrhage (ICH) accounts for $10 \%$ of all strokes [1]. Mortality associated with ICH continues to be significantly worse than in ischemic stroke. In the last 15 years, the one-month mortality rate after ICH has remained unchanged at 44\% [2], one-year survival rate remains 38\% [3], and Kaplan-Meier analysis shows an abysmal 16-year cumulative survival of only $3.2-9.8 \%$ [4].

The primary phase of ICH--hematoma expansion--remains the target of research and treatment as rapid expansion has been associated with neurological deterioration and worse outcome [5,6]. Although several factors including larger initial hematoma and heterogeneous density have been associated with greater ICH expansion [7], treatment options in this primary phase of ICH have focused on preventing hematoma expansion through blood pressure reduction in hypertensive patients and activation of coagulation.

While promoting coagulation has the potential for reducing expansion, it has not been shown to improve outcome or reduce disability [8]. However, Factor VII therapy will continue to be evaluated as identification of the CT-angiography spot sign has allowed for greater selectivity in predicting ICH expansion $[9,10]$. On the other hand, early aggressive blood pressure management within the hospital has been shown to decrease hematoma growth with the potential of reducing disability at ninety days $[11,12]$.

\section{Pre-Hospital Clinical Deterioration in Intracerebral Hemorrhage}

Many patients presenting to the emergency department with ICH will have already deteriorated due to hemorrhage expansion. Studies using CT imaging report hematoma growth in greater than $70 \%$ of patients within the first three hours of symptom onset [13] with only $11-12 \%$ expanding after the first three hours [14]. Furthermore, prehospital studies showed that substantial neurological deterioration occurred in $22 \%$ of patients with ICH between the time of paramedic arrival and emergency department admission. Clinically, as many as three in ten patients who are initially alert during paramedic evaluation within the first two hours of onset will have significantly deteriorated before arrival to the hospital [15]. These patients with pre-hospital neurological deterioration had mortality rates of $77 \%$. Initial diastolic blood pressure (DBP) also correlated with clinical deterioration [16].

These studies show that the vast majority of hematoma expansion occurs during the initial phase. This is the period of time when initial symptoms are recognized and where hematoma expansion is most volatile as evidenced by the CTA spot sign. Treatment outside of this phase is unlikely to yield significant effect on outcome, and the earliest time windows for treatment, including pre-hospital treatment of blood

${ }^{*}$ Corresponding author: Jason Chang, Department of Neurology, University of Southern California, LAC+USC Medical Center 11, 1100 N State St, A4E117, Los Angeles, CA 90033, USA, Tel: 323-409-3440; E-mail: jjwchang@hotmail.com

Received October 17, 2013; Accepted November 11, 2013; Published November 14,2013

Citation: Chang JJ, Sanossian N (2013) Pre-Hospital Glyceryl Trinitrate: Potential for Use in Intracerebral Hemorrhage. J Neurol Disord 2: 141. doi:10.4172/23296895.1000141

Copyright: ( 2013 Chang JJ, et al. This is an open-access article distributed under the terms of the Creative Commons Attribution License, which permits unrestricted use, distribution, and reproduction in any medium, provided the original author and source are credited. 
pressure may be needed to prevent clinical deterioration and obtain optimum clinical results.

\section{Blood Pressure Control as a Therapeutic Target in Intracerebral Hemorrhage Outcome}

CT-perfusion studies have shown that intensive blood pressure control does not precipitate perihematomal ischemia in ICH patients [17]. As intensive blood pressure control is safe and early hematoma growth is associated with increased mortality, prevention of this expansion through intensive blood pressure control represents a logical therapeutic target in ICH. Two major trials address the role of early intensive hospital-based blood pressure control.

In the Intensive Blood Pressure Reduction in Acute Cerebral Hemorrhage Trial (INTERACT) pilot, intensive systolic blood pressure (SBP) control (goal $<140 \mathrm{mmHg}$ ) resulted in significantly less mean proportional hematoma growth $(\mathrm{P}=0.04)$ and relative risk of hematoma growth $(\mathrm{P}=0.05)$ [11]. These promising results lead to INTERACT2, which randomized 2794 patients to intensive SBP control (goal $<140 \mathrm{mmHg}$ ) and guideline recommended SBP goals (goal $<180 \mathrm{mmHg}$ ). The primary outcome of death or disability was not significantly decreased $(\mathrm{P}=0.06)$. However, the intensive blood pressure group significantly favored secondary outcome measures such as ordinal analysis of modified Rankin scores with favorable shift of Rankin score distributions ( $\mathrm{P}=0.04)$ and physical and psychological well-being as manifested by anxiety and depression $(\mathrm{P}=0.05)$, pain or discomfort $(\mathrm{P}=0.01)$, and self-care $(\mathrm{P}=0.02)[18]$

In the Antihypertensive Treatment of Acute Cerebral Hemorrhage $(\mathrm{ATACH})$ pilot trial, 60 patients were enrolled in three tiers of increasingly intensive blood pressure goals. Primary clinical outcomes (death and severe disability defined by Rankin scores of 4 to 6) were measured at 90 days. Although primary outcome did not meet statistical significance, measured variables such as hematoma expansion, perihematomal edema, and 90-day Rankin score all showed trends favoring the intensive blood pressure control group [19]. As the pilot trial was underpowered, ATACH II, a multi-center randomized phase three trial, is currently recruiting patients to evaluate the hypothesis that intensive blood pressure lowering (goal $\mathrm{SBP}<140$ $\mathrm{mmHg}$ ) will lead to reduced death and disability outcomes at 90 days [20].

Several reasons may explain the lack of statistical significance for primary outcome found in INTERACT2 and the ATACH pilot. First may be a greater relevance of secondary mechanisms of injury in ICH--perihematomal edema, blood-brain-barrier destruction, and upregulation of inflammatory mediators--towards overall clinical outcome [21]. Second may be the relatively late times initiating therapy in both the ATACH pilot trial and INTERACT2. In ATACH, the treatment time was mean six hours after onset. In INTERACT2, median treatment time in the intensive group and standard group were 4 and 4.5 hours, respectively. However, subgroup analysis of the INTERACT pilot by quartile time periods demonstrated significant reductions in proportional hematoma growth (measured at 72 hours) ranging from $22 \%$ reduction for the $<2.9$ hour treated group to $3 \%$ reduction for the $>4.9$ hour treated group $(\mathrm{P}=0.001)$. Absolute hematoma growth, while also showing a similar trend favoring earlier treated groups, did not meet statistical significance $(\mathrm{P}=0.12)$ [22]. These findings suggest that earlier treatment of blood pressure may result in decreased hematoma volume expansion and improvement in clinical outcome. One may conclude that blood pressure control in ICH should be started as early as possible in the pre-hospital setting.

\section{Glyceryl Trinitrate as a Promising Medication for Stroke Treatment}

Glyceryl trinitrate (GTN) as a pre-hospital therapy in ICH is promising because of four properties: (1) alternative entry routes besides oral or intravenous (many ICH patients will be obtunded or have facial and swallowing weakness rendering delivery by mouth unsafe), (2) quick and graded onset of action, (3) neuroprotective effects, and (4) established record of safety.

Transdermal and sublingual GTN have been studied for many years in myocardial ischemia, congestive heart failure, and ischemic stroke. GTN acts primarily via vascular smooth muscle relaxation, which leads to arterial and venous vasodilation. This has the effect of decreasing cardiac output and improving myocardial oxygen supplyto-demand ratio. The rapid metabolism of oral GTN is circumvented through transdermal and sublingual routes. With a more rapid onset time (3 minutes) and shorter duration (10-30 minutes), sublingual GTN can be used in combination with slower onset (30-60 minutes) and longer duration transdermal GTN [23]. Transdermal and sublingual GTN showed similar mean reductions in systolic blood pressure of $9.80 \mathrm{mmHg}$ [24] and $14 \mathrm{mmHg}$ [25], respectively. Studies of transdermal GTN demonstrated that it could lower peripheral blood pressure, central blood pressure, and pulse pressure without reducing middle cerebral artery velocities and without affecting platelets [26-29].

GTN has also demonstrated neuroprotective properties in preclinical stroke models. GTN acts as an inhibitor of apoptosis [30] through formation of an $\mathrm{NO}+$ equivalent molecule that nitrosylates the redox modulatory site at the NMDA receptor. This has the neuroprotective effect of inhibiting NMDA receptormediated neurotoxicity [31]. In cerebral ischemia-reperfusion models, administration of $\mathrm{NO}$ donor was shown to decrease free radical levels [32] and reduce brain infarct volume [33], likely through release of NO, which increases blood flow to collateral blood vessels [29] and reduces monocyte and neutrophil adhesion and migration [34].

Extensive safety experience with transdermal GTN in both ischemic stroke and ICH is currently being evaluated in the Efficacy of Nitric Oxide in Acute Stroke (ENOS) trial. ENOS is enrolling 3500 acute ischemic stroke and ICH patients randomizing to GTN patch ( $5 \mathrm{mg}$ over 24 hours) or placebo. Trial enrollment is anticipated to complete in October 2013 and is nearing completion with final results anticipated within the year. Initial results from ENOS have already provided strong reassurance regarding the safety of GTN with the evaluation committee recommending completion of the trial. Included in GTN's excellent safety profile is its ability to lower blood pressure without decreasing cerebral perfusion as evidenced by preliminary data publications from the ENOS group that did not show worse 90-day clinical outcome in patients with significant $(>50 \%)$ carotid stenosis [35]. Additionally, transcranial Doppler, SPECT, and xenon CT studies of cerebral blood flow have shown that transdermal GTN increases or maintains cerebral perfusion in acute ischemic stroke patients despite decreases in mean arterial pressure $[29,36,37]$.

In $\mathrm{ICH}$, theoretical concerns regarding venodilatory effects on intracranial pressure (ICP) are nullified by actual physiologic studies in humans. In individuals with normal starting ICPs, GTN produces only minimal and transient increases in ICP [38]. In individuals with acute hemorrhagic intracranial lesions, GTN most commonly produces no elevation or even a mild reduction in ICP, likely because the raised ICP overrides the weak venodilatory signal $[29,38-40]$.

Recently, a single-center, single-blinded randomized controlled 
Citation: Chang JJ, Sanossian N (2013) Pre-Hospital Glyceryl Trinitrate: Potential for Use in Intracerebral Hemorrhage. J Neurol Disord 2: 141. doi:10.4172/2329-6895.1000141

Page 3 of 5

study, the Rapid Intervention with Glyceryl Trinitrate in Hypertensive Stroke Trial (RIGHT) evaluated the use of pre-hospital transdermal GTN in patients with ischemic stroke and ICH. Paramedics randomized 41 patients (25 in the GTN group and 16 placebo). The GTN group had SBPs significantly reduced by $21 \mathrm{mmHg}$ at 15 minutes $(\mathrm{P}=0.049)$ and $18 \mathrm{mmHg}$ at 2 hours $(\mathrm{P}=0.030)$. Blood pressure reduction was associated with improved functional outcome and significantly better 90-day Rankin score in the GTN group $(\mathrm{P}=0.017)$. Post-hoc analysis also showed a promising relationship with a correlation coefficient of $-0.296(\mathrm{P}=0.06)[41]$

\section{Alternative Drugs for Pre-hospital Blood Pressure Control}

Currently only two blood pressure medications have been studied for pre-hospital blood pressure control: GTN studied in RIGHT and lisinopril studied in PIL-FAST. In PIL-FAST, paramedics administered a crushed $5 \mathrm{mg}$ tablet of lisinopril sublingually. This medication was continued over 7 days. As a small pilot trial, 6 patients received lisinopril compared to 8 patients in the placebo arm. Comparison of pre-hospital lisinopril and GTN administration on systolic blood pressures is shown in Figure 1. As a small pilot trial, statistically significant differences in blood pressure reduction were not found between the lisinopril and placebo group. In addition, adverse events--including increase in serum creatinine, chest infection, and hypotension--were noted in the lisinopril group. Only 4 of the 14 patients completed their medication course [42].

\section{Pre-hospital Differentiation of ICH from Ischemic Stroke}

Ideally, patients with diagnosed ICH would be recruited into prehospital clinical trials of therapy. Realistically however, stroke subtype cannot be diagnosed without imaging as clinical deficits in ICH and ischemic stroke are based on lesion sites that can occur in either disease. Preliminary data on 538 patients consecutively enrolled in FAST-MAG (with 134 patients having ICH) did show ICH associated with higher SBP and DBP, younger age, less frequent atrial fibrillation, higher median Los Angeles Motor Scores (LAMS), male gender, Hispanic ethnicity, and earlier evaluation times in relation to ischemic stroke [43].

A more recent multivariable analysis of a larger dataset of 731 cases (164 with ICH) was performed by randomly assigning to derivation and validation datasets, using all variables available at time of paramedic encounter in a backward stepdown linear, additive logistic regression and classification tree analysis. The performance of a simple logistic model using seven binary predictors (age $\leq 56$ yo, non-black ethnicity, $\mathrm{SBP}>147, \mathrm{DBP}>103$, Los Angeles Motor Scores $>3$, no atrial fibrillation, no previous stroke) showed a sensitivity of $87.2 \%$ and specificity of $67.3 \%$ with overall accuracy of $77.2 \%$. The validation dataset showed $75.4 \%$ specificity and $72.4 \%$ sensitivity [44]. These background studies suggested that a pre-hospital administered scale based on clinical variables could achieve modest accuracy in differentiating ICH from ischemic stroke, but is not effective enough in patient recruitment.

\section{Safety and Feasibility of pre-Hospital Anti-Hypertensive Therapy in Ischemic Stroke}

Pre-hospital use of anti-hypertensive treatment for ICH patients not verified by imaging will inevitably treat ischemic stroke patients. The International Stroke Trial (IST) found a U-shaped distribution of blood pressure outcomes, with both higher and lower pressures associated with poor outcomes [45]. However over the past decade, evidence has suggested that early lowering of blood pressure in patients with ischemic stroke and severe hypertension is safe and possibly beneficial. In ischemic stroke, large-scale observational studies have consistently shown that elevated blood pressure is associated with worse outcomes [46-48]. In fact, elevated blood pressure in the setting of failed autoregulation may increase cerebral edema and hemorrhagic transformation [49]. Several randomized clinical trials, including ACCESS, COSSACS, and CHHIPS, have now reported that early initiation of antihypertensive therapy in acute ischemic stroke is safe and efficacious and may improve clinical outcome [50-52].

Moreover, for patients eligible for thrombolysis who are also severely hypertensive with $\mathrm{SBP}>185 \mathrm{mmHg}$, early initiation of antihypertensive therapy to reach this goal SBP is supported by positive results in multiple clinical trials [53]. In fact, active initiation of early blood pressure lowering is a recommended practice in the United

\section{Systolic Blood Pressure in RIGHT vs. PIL- FAST} (study drug vs. placebo)

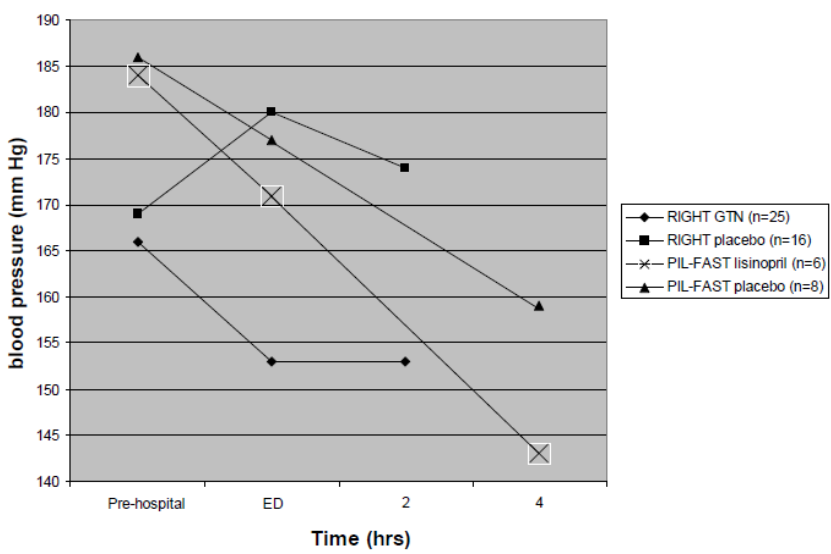

**Systolic blood pressures in RIGHT were measured at pre-hospital, Emergency Department (ED) admission, and hour 2. Systolic blood pressures in PIL-FAST were measured at pre-hospital, ED admission, hour 4, hour 24 (not shown), and day 7 (not shown).

Figure 1: Comparison of Systolic Blood pressures in Pre-hospital Administration of Glyceryl Trinitrate (RIGHT trial) and Lisinopril (PIL-FAST trial). 
Citation: Chang JJ, Sanossian N (2013) Pre-Hospital Glyceryl Trinitrate: Potential for Use in Intracerebral Hemorrhage. J Neurol Disord 2: 141. doi:10.4172/2329-6895.1000141

Page 4 of 5

\begin{tabular}{|c|c|c|c|c|}
\hline Trial & Study type & Sample size & Conclusion & Limitations \\
\hline $\begin{array}{l}\text { INTERACT2 } \\
\text {-Anderson et al. [18] }\end{array}$ & $\begin{array}{l}\text { Multi-center, prospective, ran- } \\
\text { domized, blinded }\end{array}$ & 2794 & $\begin{array}{l}\text {-Ordinal analysis showed significantly lower } 90- \\
\text { day Rankin scores }(P=0.04) \text { and psychological } \\
\text { well-being in intensive blood pressure }\end{array}$ & $\begin{array}{l}\text {-no standard blood pressure lowering } \\
\text { medication used } \\
\text {-intensive blood pressure lowering did } \\
\text { not result in reduction of primary outcome } \\
\text { (death or major disability) }\end{array}$ \\
\hline $\begin{array}{l}\text { ATACH pilot } \\
\text {-Qureshi and } \\
\text { Palesch [20] }\end{array}$ & $\begin{array}{l}\text { 3-tier, single-center, prospective, } \\
\text { blinded }\end{array}$ & 60 & $\begin{array}{l}\text {-no significant relationship between degree of } \\
\text { SBP reduction and hematoma volume, } \\
\text { perihematomal edema, and } 90 \text {-day Rankin score }\end{array}$ & $\begin{array}{l}\text {-underpowered to prove significant } \\
\text { relationships between SBP and outcome } \\
\text { variables } \\
\text {-different time points for initial recording of } \\
\text { SBP and hematoma volume, making it } \\
\text { impossible to determine if expansion simply } \\
\text { occurred because of earlier initial recording }\end{array}$ \\
\hline $\begin{array}{l}\text { PREDICT } \\
\text {-Demchuk et al. [9] }\end{array}$ & $\begin{array}{l}\text { Multi-center, prospective, } \\
\text { observational, cohort }\end{array}$ & 268 & $\begin{array}{l}\text {-CTA spot sign resulted in significantly higher } \\
90 \text {-day mortality }(P=0.001) \text {, higher } 90 \text {-day Rankin } \\
\text { score }(P<0.001) \text {, absolute ICH growth }(P<0.001) \\
\text {-sensitivity of CTA spot sign for hematoma } \\
\text { expansion }=51 \% \text {, specificity }=85 \%\end{array}$ & $\begin{array}{l}\text {-less robust pos-predictive and neg- } \\
\text { predictive value with large variability } \\
\text {-CTA spot sign reliability required } \\
\text { neuroradiologist with less robust reliability } \\
\text { for untrained site investigator } \\
\\
\text {-variability in timing of contrast bolus } \\
\text { among institutions; increased yield may } \\
\text { result from second-pass imaging } \\
\text { completed } 1 \text { min after contrast bolus }\end{array}$ \\
\hline $\begin{array}{l}\text { RIGHT } \\
\text {-Ankolekar et al. [41] }\end{array}$ & $\begin{array}{l}\text { Single-center, prospective, } \\
\text { single-blinded, randomized } \\
\text { control }\end{array}$ & 41 & $\begin{array}{l}\text {-prehospital GTN significantly lowered SBP at } 2 \\
\text { hrs }(P=0.030) \text { and improved 90-day Rankin score } \\
(P=0.017)\end{array}$ & $\begin{array}{l}\text {-small sample size } \\
\text {-single center }\end{array}$ \\
\hline $\begin{array}{l}\text { ENOS } \\
\text {-Bath et al. [27] }\end{array}$ & $\begin{array}{l}\text { Multi-center, prospective, blinded, } \\
\text { randomized control }\end{array}$ & $\begin{array}{l}3500 \\
\text { (estimated) }\end{array}$ & $\begin{array}{l}\text {-safety and efficacy of transdermal GTN in 90-day } \\
\text { clinical outcome }\end{array}$ & $-\mathrm{n} / \mathrm{a}$ \\
\hline
\end{tabular}

-SBP=systolic blood pressure

-GTN=glyceryl trinitrate

Table 1: Summary of important trials regarding Blood Pressure Control, ICH expansion, and Glyceryl Trinitrate therapy in Intracerebral Hemorrhage.

States and international treatment guidelines. Pre-hospital initiation of blood pressure control is safe and can shorten the time required for the patient to be eligible for thrombolysis.

\section{Conclusion}

Intracerebral hemorrhage is associated with poor clinical outcome and high mortality. Efforts to improve mortality have largely focused on hematoma expansion through intensive blood pressure control. Hospital-based blood pressure control may often be too late as clinical deterioration can occur immediately after ICH onset. To date, only lisinopril and GTN have been evaluated as pre-hospital medication for blood pressure control. GTN represents an ideal pre-hospital blood pressure control medication because it can be delivered via alternative transdermal or sublingual routes, has a quick and graded onset of action, has neuroprotective effects, and has an established record of safety. Its feasibility and effectiveness as a pre-hospital blood pressure medication has been evaluated through RIGHT, which showed a significant early reduction of blood pressure. As acute neurological injury requires prompt action, more emphasis on pre-hospital therapies such as GTN will become essential in future therapies (Table 1).

\section{Disclosure}

This work was funded in part by the Roxanna Todd Hodges Foundation and Joachim Splichal.

\section{Acknowledgments}

Funding for this study was provided by NIH-NINDS Award 1 U01 NS44364.

\section{References}

1. Go AS, Mozaffarian D, Roger VL, Benjamin EJ, Berry JD, et al. (2013) Heart disease and stroke statistics--2013 update: a report from the American Heart Association. Circulation 127: e6-e245

2. Flaherty ML, Haverbusch M, Sekar P, Kissela B, Kleindorfer D, et al. (2006) Long-term mortality after intracerebral hemorrhage. Neurology 66: 1182-1186.
3. Dennis MS, Burn JP, Sandercock PA, Bamford JM, Wade DT, et al. (1993) Long-term survival after first-ever stroke: the Oxfordshire Community Stroke Project. Stroke 24: 796-800.

4. Fogelholm R, Murros K, Rissanen A, Avikainen S (2005) Long term survival after primary intracerebral haemorrhage: a retrospective population based study. J Neurol Neurosurg Psychiatry 76: 1534-1538.

5. Brott T, Broderick J, Kothari R, Barsan W, Tomsick T, et al. (1997) Early hemorrhage growth in patients with intracerebral hemorrhage. Stroke 28: 1-5.

6. Lampl Y, Gilad R, Eshel Y, Sarova-Pinhas I (1995) Neurological and functional outcome in patients with supratentorial hemorrhages. A prospective study. Stroke 26: 2249-2253.

7. Barras CD, Tress BM, Christensen S, MacGregor L, Collins M, et al. (2009) Density and shape as CT predictors of intracerebral hemorrhage growth. Stroke 40: 1325-1331.

8. Mayer SA, Brun NC, Begtrup K, Broderick J, Davis S, et al. (2008) Efficacy and safety of recombinant activated factor VII for acute intracerebral hemorrhage. N Engl J Med 358: 2127-2137.

9. Demchuk AM, Dowlatshahi D, Rodriguez-Luna D, Molina CA, Blas YS et al. (2012) Prediction of haematoma growth and outcome in patients with intracerebral haemorrhage using the CT-angiography spot sign (PREDICT): a prospective observational study. Lancet Neurol 11: 307-314.

10. Brouwers HB, Falcone GJ, McNamara KA, Ayres AM, Oleinik A, et al. (2012) CTA spot sign predicts hematoma expansion in patients with delayed presentation after intracerebral hemorrhage. Neurocrit Care 17: 421-428.

11. Anderson CS, Huang Y, Wang JG, Arima H, Neal B, et al. (2008) Intensive blood pressure reduction in acute cerebral haemorrhage trial (INTERACT): a randomised pilot trial. Lancet Neurol 7: 391-399.

12. Antihypertensive Treatment of Acute Cerebral Hemorrhage (ATACH) investigators (2010) Antihypertensive treatment of acute cerebral hemorrhage. Crit Care Med 38: 637-648.

13. Davis SM, Broderick J, Hennerici M, Brun NC, Diringer MN, et al. (2006) Hematoma growth is a determinant of mortality and poor outcome after intracerebral hemorrhage. Neurology 66: 1175-1181. 
Citation: Chang JJ, Sanossian N (2013) Pre-Hospital Glyceryl Trinitrate: Potential for Use in Intracerebral Hemorrhage. J Neurol Disord 2: 141. doi:10.4172/2329-6895.1000141

14. Kazui S, Naritomi H, Yamamoto H, Sawada T, Yamaguchi T (1996) Enlargement of spontaneous intracerebral hemorrhage. Incidence and time course. Stroke 27: $1783-1787$

15. Sanossian N SS, Hamilton S, Eckstein M, Stratton S, Pratt FD, et al. (2011) for the FAST-MAG Investigators and Coordinators. Early Clinical Deterioration of Stroke Patients Assessed in the Field within Two Hours of Symptom Onset. Stroke; a journal of cerebral circulation 42: e291.

16. Moon JS, Janjua N, Ahmed S, Kirmani JF, Harris-Lane P, et al. (2008) Prehospital neurologic deterioration in patients with intracerebral hemorrhage. Crit Care Med 36: 172-175.

17. Butcher KS, Jeerakathil T, Hill M, Demchuk AM, Dowlatshahi D, et al. (2013) The Intracerebral Hemorrhage Acutely Decreasing Arterial Pressure Trial. Stroke 44: 620-626.

18. Anderson CS, Heeley E, Huang Y, Wang J, Stapf C, et al. (2013) Rapid bloodpressure lowering in patients with acute intracerebral hemorrhage. $\mathrm{N}$ Engl J Med 368: 2355-2365

19. Qureshi AI, Palesch YY, Martin R, Novitzke J, Cruz-Flores S, et al. (2010) Effect of systolic blood pressure reduction on hematoma expansion, perihematomal edema, and 3-month outcome among patients with intracerebral hemorrhage: results from the antihypertensive treatment of acute cerebral hemorrhage study. Arch Neurol 67: 570-576.

20. Qureshi Al, Palesch YY (2011) Antihypertensive Treatment of Acute Cerebral Hemorrhage (ATACH) II: design, methods, and rationale. Neurocrit Care 15: 559-576.

21. Belur PK, Chang JJ, He S, Emanuel BA, Mack WJ (2013) Emerging experimental therapies for intracerebral hemorrhage: targeting mechanisms of secondary brain injury. Neurosurg Focus 34: E9.

22. Arima H, Huang Y, Wang JG, Heeley E, Delcourt C, et al. (2012) Earlier blood pressure-lowering and greater attenuation of hematoma growth in acute intracerebral hemorrhage: INTERACT pilot phase. Stroke 43: 2236-2238.

23. Chien YW (1984) Pharmaceutical considerations of transdermal nitroglycerin delivery: the various approaches. Am Heart J 108: 207-216.

24. Gray LJ, Sprigg N, Rashid PA, Willmot MR, Bath PM (2006) Effect of nitric oxide donors on blood pressure and pulse pressure in acute and subacute stroke. J Stroke Cerebrovasc Dis 15: 245-249.

25. Wuerz R, Swope G, Meador S, Holliman CJ, Roth GS (1994) Safety of prehospital nitroglycerin. Ann Emerg Med 23: 31-36.

26. Butterworth RJ, Cluckie A, Jackson SH, Buxton-Thomas M, Bath PM (1998) Pathophysiological assessment of nitric oxide (given as sodium nitroprusside) in acute ischaemic stroke. Cerebrovasc Dis 8: 158-165.

27. Bath PM, Pathansali R, Iddenden R, Bath FJ (2001) The effect of transdermal glyceryl trinitrate, a nitric oxide donor, on blood pressure and platelet function in acute stroke. Cerebrovasc Dis 11: 265-272.

28. Rashid P, Weaver C, Leonardi-Bee J, Bath F, Fletcher S, et al. (2003) The effects of transdermal glyceryl trinitrate, a nitric oxide donor, on blood pressure, cerebral and cardiac hemodynamics, and plasma nitric oxide levels in acute stroke. J Stroke Cerebrovasc Dis 12: 143-151.

29. Willmot M, Ghadami A, Whysall B, Clarke W, Wardlaw J, et al. (2006) Transdermal glyceryl trinitrate lowers blood pressure and maintains cerebral blood flow in recent stroke. Hypertension 47: 1209-1215.

30. Willmot MR, Bath PM (2003) The potential of nitric oxide therapeutics in stroke. Expert Opin Investig Drugs 12: 455-470.

31. Lipton SA, Choi YB, Pan ZH, Lei SZ, Chen HS, et al. (1993) A redox-based mechanism for the neuroprotective and neurodestructive effects of nitric oxide and related nitroso-compounds. Nature 364: 626-632.

32. Cho HG, Shin HK, Shin YW, Lee JH, Hong KW (2003) Role of nitric oxide in the CBF autoregulation during acute stage after subarachnoid haemorrhage in rat pial artery. Fundam Clin Pharmacol 17: 563-573.

33. Pluta RM, Rak R, Wink DA, Woodward JJ, Khaldi A, et al. (2001) Effects of nitric oxide on reactive oxygen species production and infarction size after brain reperfusion injury. Neurosurgery 48: 884-892.

34. Bath PM (1993) The effect of nitric oxide-donating vasodilators on monocyte chemotaxis and intracellular cGMP concentrations in vitro. Eur J Clin Pharmacol 45: 53-58.

35. Sare GM, Gray LJ, Wardlaw J, Chen C, Bath PM, et al. (2009) Is lowering blood pressure hazardous in patients with significant ipsilateral carotid stenosis and acute ischaemic stroke? Interim assessment in the 'Efficacy of Nitric Oxide in Stroke' trial. Blood Press Monit 14: 20-25.

36. Dahl A, Russell D, Nyberg-Hansen R, Rootwelt K (1989) Effect of nitroglycerin on cerebral circulation measured by transcranial Doppler and SPECT. Stroke 20: $1733-1736$.

37. Moppett IK, Sherman RW, Wild MJ, Latter JA, Mahajan RP (2008) Effects of norepinephrine and glyceryl trinitrate on cerebral haemodynamics: transcranial Doppler study in healthy volunteers. Br J Anaesth 100: 240-244.

38. Iwanaga H, Okuchi K, Koshimae N, Goda K, Imanishi M, et al. (1995) Effects of intravenous nitroglycerin combined with dopamine on intracranial pressure and cerebral arteriovenous oxygen difference in patients with acute subarachnoid haemorrhage. Acta Neurochir (Wien) 136: 175-180.

39. Kamiya K, Yamashita N, Mizawa I, Nagai H (1989) [Post-operative blood pressure management by nitroglycerin in the field of neurosurgery]. No Shinkei Geka 17: 521-524.

40. Matsuyama T, Aoyama N, Tsukamoto M (1992) [Intentional hypotension therapy induced by nitroglycerin and the changes in the intracranial pressure for acute hemorrhagic intracranial lesions]. No Shinkei Geka 20: 1149-1154.

41. Ankolekar S, Fuller M, Cross I, Renton C, Cox P, et al. (2013) Feasibility of an Ambulance-Based Stroke Trial, and Safety of Glyceryl Trinitrate in Ultra-Acute Stroke: The Rapid Intervention With Glyceryl Trinitrate in Hypertensive Stroke Trial (RIGHT, ISRCTN66434824). Stroke 44: 3120-3128.

42. Shaw L, Price C, McLure S, Howel D, McColl E, et al. (2013) Paramedic Initiated Lisinopril For Acute Stroke Treatment (PIL-FAST): results from the pilot randomised controlled trial. Emerg Med J.

43. Sanossian N, Hamilton S, Liebeskind DS, Ali LK, Restrepo L, et al. (2009) Clinical Features Distinguishing Hemorrhagic and Ischemic Stroke in the First Two Hours after Onset. Neurology 72: S3 A293.

44. Sanossian N, Hamilton S, Liebeskind DS, Ali LK, Restrepo L, et al. (2010) FAST-MAG Investigators and Nurses. Development and Validation of a Clinical Scale Distinguishing Hemorrhagic and Ischemic Stroke in the First Two Hours after Onset. Stroke 41: e56.

45. (1997) The International Stroke Trial (IST): a randomised trial of aspirin subcutaneous heparin, both, or neither among 19435 patients with acute ischaemic stroke. International Stroke Trial Collaborative Group. Lancet 349: 1569-1581.

46. Leonardi-Bee J, Bath PM, Phillips SJ, Sandercock PA; IST Collaborative Group (2002) Blood pressure and clinical outcomes in the International Stroke Trial. Stroke 33: 1315-1320.

47. Dandapani BK, Suzuki S, Kelley RE, Reyes-Iglesias Y, Duncan RC (1995) Relation between blood pressure and outcome in intracerebral hemorrhage. Stroke 26: 21-24.

48. Willmot M, Leonardi-Bee J, Bath PM (2004) High blood pressure in acute stroke and subsequent outcome: a systematic review. Hypertension 43: 18-24.

49. Tietjen CS, Hurn PD, Ulatowski JA, Kirsch JR (1996) Treatment modalities for hypertensive patients with intracranial pathology: options and risks. Crit Care Med 24: 311-322.

50. Schrader J, Lüders S, Kulschewski A, Berger J, Zidek W, et al. (2003) The ACCESS Study: evaluation of Acute Candesartan Cilexetil Therapy in Stroke Survivors. Stroke 34: 1699-1703.

51. Potter JF, Robinson TG, Ford GA, Mistri A, James M, et al. (2009) Controlling hypertension and hypotension immediately post-stroke (CHHIPS): a randomised, placebo-controlled, double-blind pilot trial. Lancet Neurol 8: 48-56.

52. Robinson TG, Potter JF, Ford GA, Bulpitt CJ, Chernova J, et al. (2010) Effects of antihypertensive treatment after acute stroke in the Continue or Stop PostStroke Antihypertensives Collaborative Study (COSSACS): a prospective, randomised, open, blinded-endpoint trial. Lancet Neurol 9: 767-775.

53. Lees KR, Bluhmki E, von Kummer R, Brott TG, Toni D, et al. (2010) Time to treatment with intravenous alteplase and outcome in stroke: an updated pooled analysis of ECASS, ATLANTIS, NINDS, and EPITHET trials. Lancet 375: 16951703. 